\title{
Epidemiology Nursing
}

National Cancer Institute

\section{Source}

National Cancer Institute. Epidemiology Nursing. NCI Thesaurus. Code C20895.

The application of nursing principles to the study of the patterns of disease or other events across populations. 